\title{
Erratum to 'Second-line targeted therapies after nivolumab-ipilimumab failure in metastatic renal cell carcinoma' [Eur J Cancer 108 (February 2019) 33-40]
}

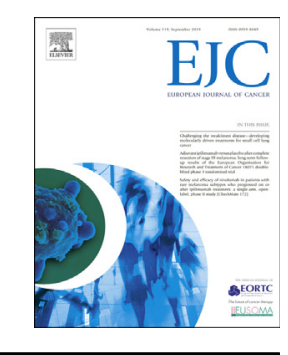

Marie Auvray ${ }^{a}$, Edouard Auclin ${ }^{\text {b,c,d }}$, Philippe Barthelemy ${ }^{\mathrm{e}}$, Petri Bono ${ }^{\mathrm{f}}$, Pirkko Kellokumpu-Lehtinen ${ }^{\text {g }}$, Marine Gross-Goupil h, Guillermo De Velasco i, Thomas Powles j, Guillaume Mouillet k, Yann-Alexandre Vano ${ }^{1}$, Gwenaëlle Gravis ${ }^{m}$, Loïc Mourey ${ }^{n}$, Franck Priou ${ }^{\circ}$, Frédéric Rolland ${ }^{p}$, Bernard Escudier ${ }^{\mathrm{a}}$, Laurence Albiges ${ }^{\text {a,* }}$

${ }^{a}$ Medical Oncology, Gustave Roussy, Université Paris-Saclay, Villejuif, France

${ }^{\mathrm{b}}$ Gastrointestinal Oncology Department, European Georges Pompidou Hospital, Université René Descartes, Paris, France

${ }^{\mathrm{c}}$ Methodology and Quality of Life Unit in Oncology, University Hospital of Besançon, Besançon, France

${ }^{\mathrm{d}}$ Univ. Bourgogne Franche-Comté, INSERM, EFS BFC, UMR1098, Interactions Hôte-Greffon-Tumeur/Ingénierie Cellulaire et Génique, F-25000, Besançon, France

${ }^{\mathrm{e}}$ Medical Oncology, Hôpitaux Universitaires de Strasbourg, Strasbourg, France

${ }^{\mathrm{f}}$ Comprehensive Cancer Center, Helsinki University Hospital and University of Helsinki, Helsinki, Finland

${ }^{\mathrm{g}}$ Department of Oncology, Tampere University Hospital and University of Tampere, Tampere, Finland

${ }^{\mathrm{h}}$ Oncology Department, Centre Hospitalier Universitaire, Bordeaux, Aquitaine, France

${ }^{\mathrm{i}}$ Department of Medical Oncology, University Hospital 12 de Octubre, I +12, Madrid, Spain

${ }^{\mathrm{j}}$ Barts Cancer Institute, Queen Mary University of London, London, UK

${ }^{\mathrm{k}}$ Department of Medical Oncology, University Hospital, Besançon, France

${ }^{1}$ Oncology Department, European Georges Pompidou Hospital, Université René Descartes, Paris, France

${ }^{\mathrm{m}}$ Medical Oncology, Institut Paoli-Calmettes, Marseille, France

${ }^{\mathrm{n}}$ Department of Oncology, Institut Claudius Regaud, IUCT-Oncopole, Toulouse, France

${ }^{\circ}$ Department of Oncology, Centre Hospitalier Départemental Les Oudairies, La Roche-sur-Yon, France

${ }^{\mathrm{p}}$ Medical Oncology, Institut René Gauducheau, Saint Herblain, France

The publisher regrets the conflict of interest information provided by the authors was not included in the paper and instead the incorrect statement 'None declared' was published. The publisher would like to apologise for any inconvenience caused.

DOI of original article: https://doi.org/10.1016/j.ejca.2018.11.031.

* Corresponding author: Medical Oncology, Gustave Roussy, Université Paris-Saclay, Villejuif, France. Fax: +33142115305.

E-mail address: laurence.albiges@gustaveroussy.fr (L. Albiges).
Please see below the statement provided by the authors:

G.D.V. declared consultancy or advisory role for Janssen, Pfizer, Novartis, Bayer and Astellas-Medivation and funding from Ipsen. P.Ba. declared consultancy or advisory role for Pfizer, Novartis, Ipsen, Bristol-Myers Squibb (BMS), Roche, Merck, and Janssen. G.M. declared consultancy or advisory role for Pfizer, Novartis, Ipsen, BMS and Janssen. Y.-A.V. declared receiving honoraria and consulting or advisory role for Pfizer, Novartis, BMS, 
Ipsen, Roche, Astellas, Janssen and Sanofi. M.G.-G. declared receiving travel fee from PFIZER, BMS and Novartis. L.M. declared receiving honoraria from Sanofi, Astellas, Janssen, Pfizer, Ipsen and BMS. F.R. declared consulting or advisory role for Novartis, Pfizer, BMS, Janssen and Ipsen. B.E. declared receiving honoraria and consulting or advisory role for Bayer, Novartis, Pfizer, Exelixis, BMS, Ipsen, EUSA Pharma, Roche and Genentech. L.A. declared consulting or advisory role for Novartis, Pfizer, Amgen, BMS, Ipsen, Roche, Astellas and Merck. M.A., E.A., P.Bo., T.P., G.G. and F.P. declared no conflict of interest. 